\title{
Real-time analysis of soot emissions from bituminous coal pyrolysis and combustion with a vacuum ultraviolet photoionization aerosol time-of-flight mass spectrometer
}

\author{
Shaokai Gao, Yang Zhang, Junwang Meng, Jinian Shu* \\ Research Center for Eco-Environmental Sciences, Chinese Academy of Sciences, Beijing, 100085, China
}

\section{A R T I C L E D A T A}

Article history:

Received 21 May 2008

Received in revised form

30 September 2008

Accepted 13 October 2008

Keywords:

Aerosol mass spectrometry

Aerosol chemistry

PAHs

Soot emission

Pyrolysis

Combustion

\begin{abstract}
A B S T R A C T
This paper reports on-line analyses of the soot emissions from the Inner Mongolia bituminous coal combustion and pyrolysis processes with a vacuum ultraviolet photoionization aerosol time-of-flight mass spectrometer (VUV-ATOFMS). The soot particles are generated by heating a small amount of screened coal powder in synthetic air and nitrogen atmosphere in a tubular oven. The vacuum ultraviolet photoionization time-of-flight (VUV-TOF) mass spectra of the soot particles emitted from combustion and pyrolysis at different oven temperatures and different stages are obtained. The VUV-TOF mass spectra are assigned with the references of the results of the off-line GC/MS analysis.
\end{abstract}

(C) 2008 Elsevier B.V. All rights reserved.

\section{Introduction}

Coal smoke makes a large contribution to global air pollution due to the fact that coal is one of the major fossil fuels. Coal accounts for approximately $27 \%$ of the total primary energy consumption of the world (Cooke et al., 1999). Both coal combustion and pyrolysis processes emit large amounts of carbonaceous aerosols. Aromatic compounds in these aerosols get special attention due to their great potential carcinogenic, mutagenic and genotoxic effects on human health (Lighty et al., 2000).

Many researchers have focused on the emission characteristics of both the particulate phase and the gas phase from coal combustion and pyrolysis using a variety of conventional scientific instruments such as GC/MS (Greenwood et al., 1993; Olivella et al., 2002; Chen et al., 2005), HPLC (Ledesma et al., 2000) and FTIR (Ibarra and Moliner, 1991; Baxter et al., 1993; Arenillas et al., 2004) etc. All of these methods involve the isolation of particles on filters with subsequent analysis performed in the laboratory. These isolation processes often disturb the original constituents and thus render the data questionable because of potential evaporation or reaction of the particles before analysis. To overcome these difficulties, fast and in situ mass spectrometric techniques, especially aerosol mass spectrometers combining with soft ionization methods, e.g. vacuum ultraviolet (VUV) photoionization techniques (Woods et al., 2001; Sykes et al., 2002; Oktem et al., 2004; Mysak et al., 2005; Gloaguen et al., 2006; Canagaratna et al., 2007; Northway et al., 2007; Streibel et al., 2007) have been developed, enabling on-line analyses of the chemical compositions of aerosols. VUV photoionization is a soft ionization technique; the organic molecules undergo much less fragmentation during the VUV photoionization process compared with the electron impact (EI) ionization (Northway et al., 2007). Therefore, VUV photoionization mass spectra are

\footnotetext{
* Corresponding author. Tel.: +8610 62849508; fax: +861062923563.

E-mail address: jshu@rcees.ac.cn (J. Shu).
} 
more easily assigned than EI mass spectra. However, large variations in photoionization potentials and photoionization cross-sections between molecules result in large variations of the sensitivity of this method for detecting different molecules (Gao et al., 2008).

Since the first on-line mass spectrometric analysis of single particles in 1973 (Davis, 1973), many researchers have focused on the emission factors of different sources including gasoline and diesel engine (Oudejans et al., 2004; Toner et al., 2006), wood burning (Schneider et al., 2006) and cigarette smoke (Dall'Osto et al., 2007) etc., whereas relatively little has been carried out on the characterization of coal soot with an aerosol mass spectrometer. This paper presents on-line analyses of the coal soot produced at different combustion/pyrolysis times and temperatures with a newly home-built vacuum ultraviolet photoionization aerosol time of flight mass spectrometer (VUV-ATOFMS). This real-time analysis mainly focuses on the PAH compounds contained in the soot particles as the ATOFMS is more sensitive to PAH compounds than others (Gao et al., 2008).

\section{Experiment}

The schematic diagram of the experimental setup is shown in Fig. 1. The VUV-ATOFMS was newly home-built to analyze organic particles on a real-time, quantitative basis. A detailed description has been given elsewhere (Shu et al., 2008). Briefly, samples are introduced into the instrument through a nozzle with $\sim 0.12 \mathrm{~mm}$ orifice, and then the aerosol particles are focused into a particle beam with a diameter of $\sim 1 \mathrm{~mm}$ by an aerodynamic lens assembly. A three stage differential pumping system, which is composed of a source chamber, a differential chamber, and a detection chamber, is used to directly sample the particles at a flow rate of $\sim 1.3 \mathrm{~cm}^{3} \mathrm{tm} \mathrm{s}^{-1}$ at atmospheric pressure. An $8 \mathrm{~mm}$ diameter copper rod coupled with a cartridge heater is used to vaporize the particles. A VUV lamp that has a

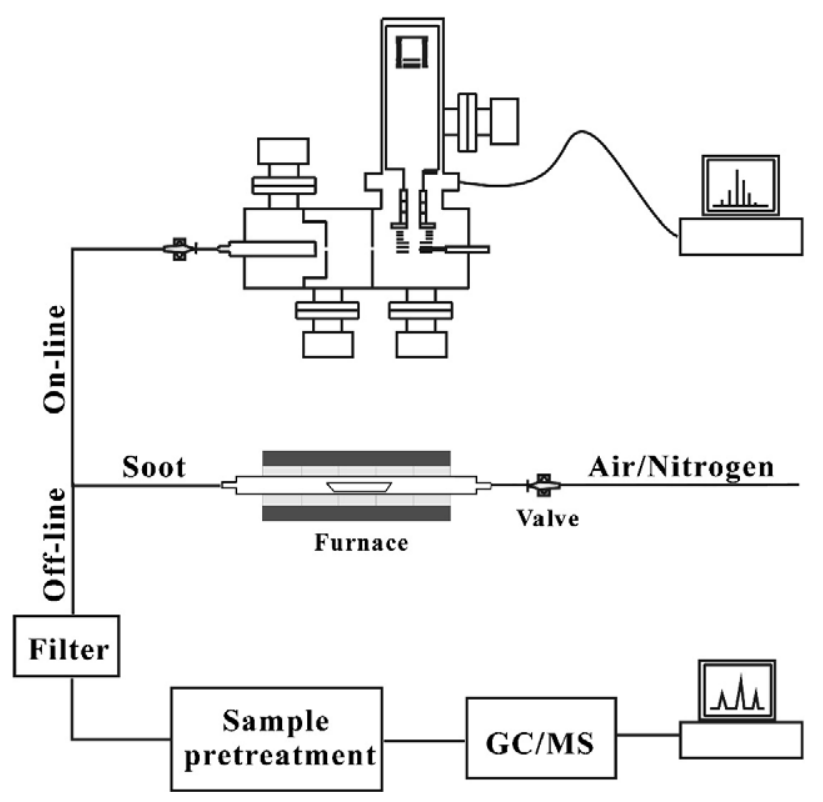

Fig. 1-Schematic diagram of the experimental setup. main energy output at $10 \mathrm{eV}(123.6 \mathrm{~nm}, \mathrm{Kr}$ resonance line) is used as the ionization source with a total photon flux output of about $2 \times 10^{12}$ photon/s. A $0.41 \mathrm{~V} / \mathrm{cm}$ electric field is used to drive the ions into the second stage of ion optics where a positive electric pulse repels the ions into the reflectron mass spectrometer with a field free flight distance of $1.4 \mathrm{~m}$, an ion mirror and a chevron multichannel plate detector. The pulse is provided with a HTS31 fast high voltage transistor switch (Behlke Electronic GMBH, Germany). The repetition rate of the pulses is optimized to $10 \mathrm{kHz}$ in this experiment.

The Inner Mongolia bituminous (IMB) coal is selected because of its abundant content in China. The IMB coal is ground into a 75-mesh. A tubular oven with a quartz tube insert (i.d. $30 \mathrm{~mm}$ ) is used for the combustion and pyrolysis experiments. In these experiments, the heating of coal in air is defined as combustion, while heating in nitrogen is defined as pyrolysis. The oven temperature is set to $673,873,1073$ and $1273 \mathrm{~K}$ respectively. A $\sim 1.5 \mathrm{l} / \mathrm{min}$ flow of synthetic air (80\% nitrogen, $20 \%$ oxygen) is provided for the combustion experiment while a $1.5 \mathrm{l} / \mathrm{min}$ flow of high purity nitrogen is maintained for the pyrolysis experiment. After passing through a $2.5 \mathrm{~m}$ long conductive rubber tube, the soot particles entrained in the flow are continuously sampled and analyzed with the VUVATOFMS. The temperature of the thermal heater is optimized to be $393 \mathrm{~K}$ in order to minimize the fragmentation and maximize the signal intensities of the organic compounds. Generally, the complete heating process for $10 \mathrm{~g}$ coal powder in air or nitrogen atmospheres ranges in time from tens of seconds to minutes with different oven temperatures. For off-line analysis, a glass fiber filter is placed at the outlet of the furnace ( $873 \mathrm{~K}$ ) to separate particles from the gas stream. Then the filter is ultrasonically extracted 3 times in dichloride methane (DCM), a process which lasts for $20 \mathrm{~min}$. The extracts are combined and concentrated to about $1 \mathrm{ml}$ on a rotary evaporator. Finally, the extracts are dried under a gentle stream of high purity nitrogen and re-dissolved in hexane to about $1 \mathrm{ml}$. Interfering species such as the sticky oily matter contained in the extract are removed by liquid-solid chromatography using a silica column (the silica was preheated at $423 \mathrm{~K}$ for $12 \mathrm{~h}$ ). We speculate that these are from coal tar which contains lots of organic compounds with high molecular weights and small solubility; identifying such compounds is beyond the scope of this research. Finally, the aliphatic and aromatic fractions are respectively eluted out by $100 \mathrm{ml}$ hexane and $150 \mathrm{ml}$ mixture of DCM and hexane (1:1 V/V). The two fractions are respectively concentrated to approximately $0.5 \mathrm{ml}$ using the same procedure described above. All samples are analyzed using a Hewlett-Packard 6890 gas chromatograph equipped with a $30 \mathrm{~m} \times 0.25 \mathrm{~mm} \times 0.25 \mu \mathrm{m} \mathrm{HP}-5$ capillary, and coupled to a HP-5973 quadrupole mass filter with a $70 \mathrm{eV}$ electron impact ionizer. The chromatographic conditions are as follows: injector temperature, $553 \mathrm{~K}$; ion source temperature, $453 \mathrm{~K}$; the temperature program begins at $338 \mathrm{~K}$, after a hold for $5 \mathrm{~min}$, then increases to $563 \mathrm{~K}$ at $5 \mathrm{~K} / \mathrm{min}$, with another isothermal hold at $563 \mathrm{~K}$ for $20 \mathrm{~min}$. The carrier gas is helium at a constant flow rate of $1.5 \mathrm{ml} / \mathrm{min}$. The sample of $1 \mu \mathrm{l}$ is injected with a splitless model. A mass range from 50 to $510 \mathrm{Da}$ is used for qualitative determination. The chromatographic peaks of the samples are identified by comparison of mass spectra with the literature and library data (NIST mass search, version 2005) (matching degree $>90 \%$ ). 
The original organic contents contained in coal are analyzed with the VUV-ATOFMS and the GC/MS. 20 g 75-meshed coal powder is extracted ultrasonically 3 times each with $100 \mathrm{ml}$ DCM. Each extraction lasts for $20 \mathrm{~min}$. The organic extracts are filtered with filter paper. The three filtered extracts are mixed together. One portion of the extract is introduced into the VUVATOFMS after atomization. The other is fractionated, concentrated and stored at $277 \mathrm{~K}$ for GC/MS analysis.

All reagents are of chromatographic grade, from J. T. Baker Co. The anhydrous sodium sulfate (analytical grade) and the silica gel (chromatographic grade 100-200 mesh) are purchased from QingDao Chemical Plant in China. The IMB coal is purchased from a coal storage and transportation station in Beijing.

\section{Results and discussion}

The GC/MS total ion chromatogram and the VUV-TOF mass spectrum of the IMB coal extracts are shown in Fig. 2(A and B), respectively. Each GC/MS TIC and the VUV-TOF mass spectrum is normalized with the value of the most intense peak. The dominant peak in Fig. 2(A) is 3,4,5,6-tetramethylphenanthrene assigned by matching its daughter ion pattern with the standard database(NIST mass search, version 2005). Other major peaks shown in Fig. 2(A) which can be iden-
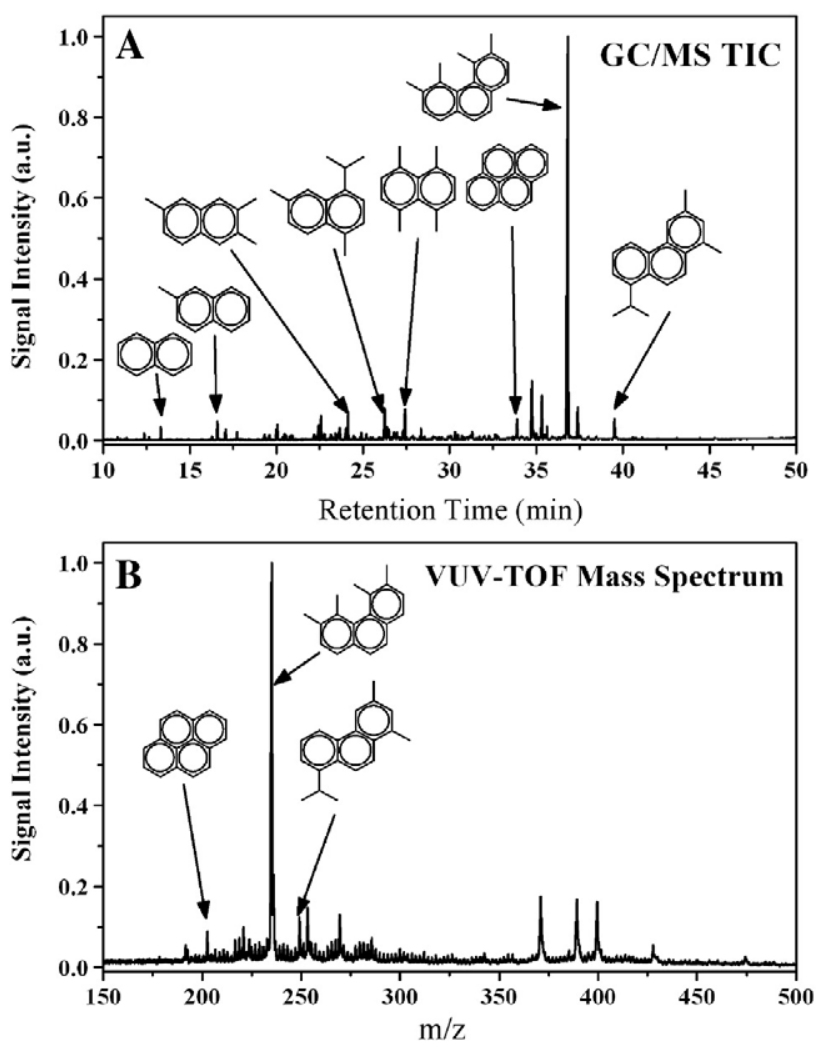

Fig. 2-GC/MS total ion chromatogram (A) and VUV-TOF mass spectrum (B) of the coal extract. The GC/MS total ion chromatogram and the VUV-TOF mass spectrum are normalized with the values of their most intense peaks, respectively. tified with the standard database are naphthalene, 2-methylnaphthalene, 2,3,6-naphthalene, 4-isopropyl-1,6-dimethylnaphthalene, 1,4,5,8-naphthalene, pyrene, and, 4-isopropyl1,3-dimethyl-phenanthrene. The VUV-TOF mass spectrum shown in Fig. 2(B) shows a very intense peak at $234 \mathrm{Da}$, which is assigned to 3,4,5,6-tetramethyl-phenanthrene according to the GC/MS TIC results. The mass peaks of pyrene and 4isopropyl-1,3-dimethyl-phenanthrene also appear in Fig. 2(B). However, naphthalene and its analogues are absent in the VUVTOF mass spectrum shown in Fig. 2(B). We think that the chemicals with lighter molecular weights might be lost to gas phase during atomization, and thus are not detected by the ATOFMS. Contrary to this phenomenon, the chemicals with heavier molecular weights $(>250)$ are not detected by GC/MS sensitively. We think that the capillary temperature of the GC/ MS may be not high enough to vaporize the chemicals with heavier molecular weights efficiently. The difference between Fig. 2(A) and (B) may reflect the difference of the sensitivities between the GC/MS and the VUV-ATOFMS. Fig. 2 shows that 3,4,5,6-tetramethyl-phenanthrene is abundant in the IMB coal. The VUV-TOF mass spectrum of the coal extract offers a good reference for the VUV-TOF mass spectra of soot particles below.

Fig. 3 shows the VUV-TOF mass spectra of coal soot particles generated from pyrolysis $(\mathrm{a}-\mathrm{d})$ and combustion $(\mathrm{A}-\mathrm{D})$ with oven temperatures of $673 \mathrm{~K}(\mathrm{a}, \mathrm{A}), 873 \mathrm{~K}(\mathrm{~b}, \mathrm{~B}), 1073 \mathrm{~K}(\mathrm{c}, \mathrm{C})$, and $1273 \mathrm{~K}$ $(d, D)$, respectively. The mass spectra are all collected for $30 \mathrm{~s}$ when the density of soot generated roughly reaches its maximum. They are each normalized with the value of the most intense peak of the individual spectrum. Fig. 3(a, b, A) shows a very intense peak at $234 \mathrm{Da}$, which is also observed in Fig. 2(B). These phenomena indicate that 3,4,5,6-tetramethyl phenanthrene, the original organic content contained in coal, is vaporized from coal powder and condenses on soot particles at low or medium temperatures during combustion or pyrolysis process $(673-873 \mathrm{~K})$. Fig. 3(b) shows the signals of aryl-PAHs prevailing while Fig. 3(B) shows obvious signals of oxygen containing PAHs (O-PAHs). This may be an indication of the participation of oxygen in the reaction during combustion process. Fig. 3(D) shows that the main peaks are at $178 \mathrm{Da}$, $202 \mathrm{Da}, 226 \mathrm{Da}, 228 \mathrm{Da}, 252 \mathrm{Da}$ and $276 \mathrm{Da}$, which are assigned to phenanthrene, pyrene, cyclopenta[cd]pyrene, benzo[a] anthrene, benzo[a]pyrene and indeno[1,2,3-cd]pyrene respectively according to the GC/MS TIC results. In Fig. 3(d), besides the mass peaks shown in Fig. 3(D), it shows much stronger mass peaks at $152 \mathrm{Da}, 166 \mathrm{Da}, 190 \mathrm{Da}, 216 \mathrm{Da}, 242 \mathrm{Da}$, which respectively represent acenaphthylene, fluorene, $4 \mathrm{H}$-cyclopenta [def]phenanthrene, mono-methylated pyrene and monomethylated chrysene (Gao et al., 2008).

The spectral differences between Fig. 3(a) and (A) as well as Fig. 3(b) and (B) indicate obviously different reaction mechanisms for pyrolysis and combustion at relatively lower oven temperatures (i.e. $<873 \mathrm{~K}$ ). Compared with Fig. 3(b and B), the mass spectra of the soot particles generated from the pyrolysis (Fig. 3(c)) and combustion (Fig. 3(C)) processes of the coal at $1073 \mathrm{~K}$ become sparser. This means that the unstable compounds in soot particles are consumed by pyrolysis or combustion at much higher oven temperatures. Fig. 3(d) and (D) shows that most of the substituted PAHs such as aryl-PAHs, and oxygen containing PAHs (O-PAHs) are reduced to their skeletal structures, and only the most thermally stable compounds 


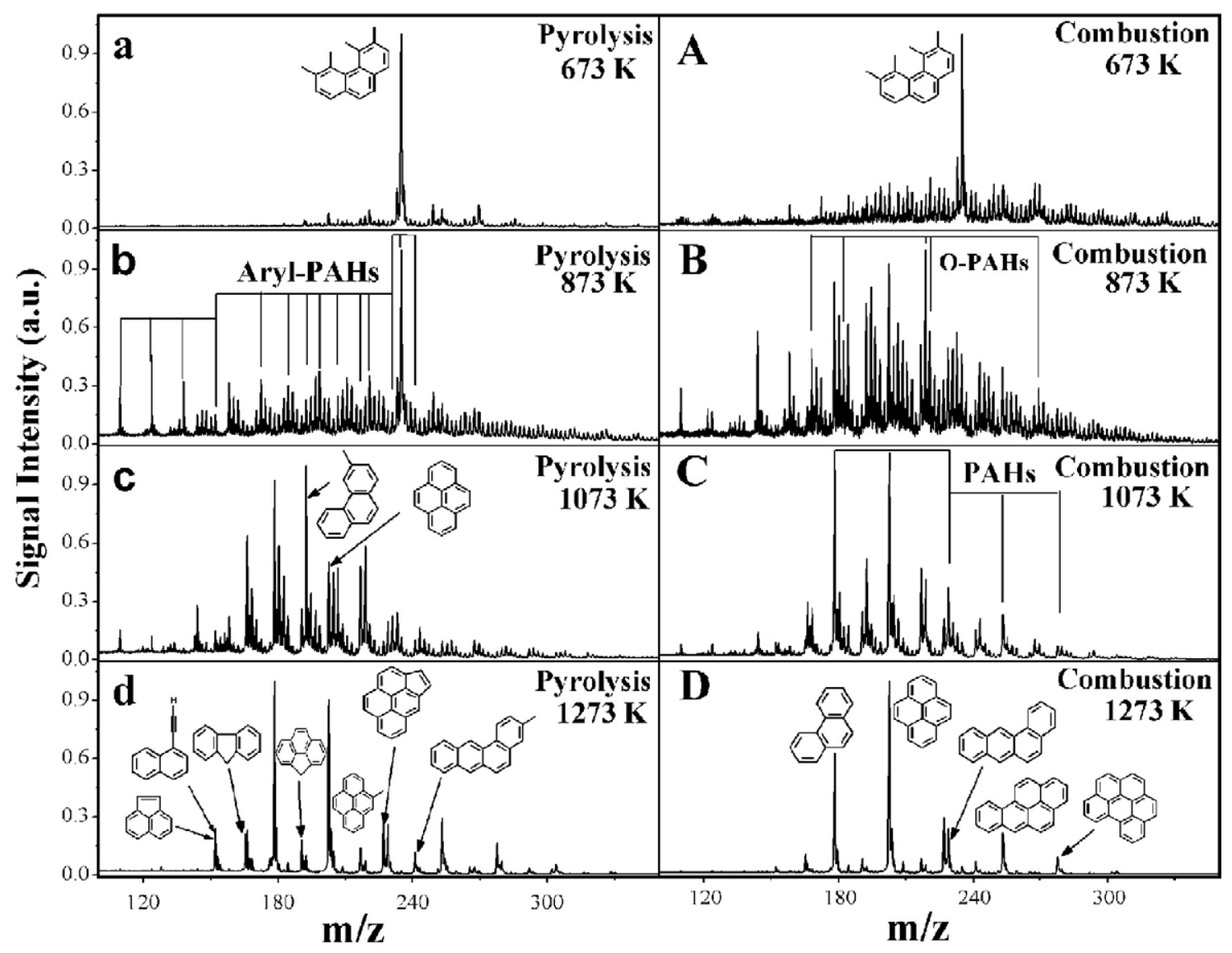

Fig. 3-VUV-TOF mass spectra of coal soot particles generated from pyrolysis (a-d) and combustion (A-D) at different oven temperatures. The mass spectra are all collected for $30 \mathrm{~s}$ when the density of soot generated reaches around its maximum. They are all normalized with the value of the most intense peak of each. The temperatures of the tube oven are $673 \mathrm{~K}(\mathrm{a}, \mathrm{A}), 873 \mathrm{~K}(\mathrm{~b}, \mathrm{~B})$, $1073 \mathrm{~K}(\mathrm{c}, \mathrm{C})$, and $1273 \mathrm{~K}$ (d, D) for pyrolysis and combustion.

without any functional groups prevail on the VUV-TOF mass spectra of soot particles. This indicates a more thorough combustion or pyrolysis process at $1273 \mathrm{~K}$ (Cao et al., 2003). These results reveal that the oven temperature is critical to the measurement of the composition of soot emissions.

Fig. 4 shows the VUV-TOF mass spectra of the coal soot particles generated at different stages of pyrolysis (Fig. $4(a-c)$ ) and combustion processes (Fig. $4(\mathrm{~A}-\mathrm{C})$ ) at $873 \mathrm{~K}$. The oven temperature of $873 \mathrm{~K}$ is selected because the reaction times of pyrolysis and combustion at that temperature are in the response range of the ATOFMS. Fig. 4(a), (b) and (c) are respectively collected at $140 \mathrm{~s}, 350 \mathrm{~s}$ and $525 \mathrm{~s}$ while Fig. 4(A), (B) and (C) are respectively collected at $65 \mathrm{~s}, 135 \mathrm{~s}$ and $240 \mathrm{~s}$. The time is recorded after the coal sample is delivered into the center of the tube oven. It takes about $1 \mathrm{~min}$ for the carrier gas to transport the nascent soot particles from the tubular oven to the VUV-ATOFMS. The times are selected to represent three different stages of the pyrolysis or combustion experiment, i.e. initial stage, intermediate stage and terminal stage. Fig. 4(a) is similar to Fig. 2(B), which means that the constituents of soot particles formed in early stage of pyrolysis are mainly contributed from non-decomposed organics contained in coal. Fig. 4(b) shows that there are many new species formed in the mid stage of the pyrolysis. These new species may come from the large pyrolysis fragments or the repolymerization of some small pyrolysis fragments. A detailed description of the PAHs formation mechanism has been given by Richter and Howard (2000). Fig. 4(A-C) shows significant differences from Fig. 4(a-c). The intense mass peaks at the $m / z 234$ shown in Fig. $4(a-c)$ are absent in Fig. 4(A-C). This phenomenon indicates the vapor that the organics emitted from coal decomposes completely at the early stage of combustion. Fig. 4(A-C) shows that the shapes of the mass spectra of the soot particles produced at different stages of the combustion at $873 \mathrm{~K}$ are similar, which means that chemical compositions of those particles are similar.

Fig. 5 shows the particle-phase emissions of phenanthrene, 3,4,5,6-tetramethylated phenanthrene, benzo[b]naphtho[2,3d]furan/benzo[k,l]-xanthene at different combustion and pyrolysis times at $873 \mathrm{~K}$. Every data point shows the peak intensity of the corresponding compound on the VUV-TOF mass spectra. Here we assume that the ionization efficiencies of the three compounds are equal based on their benzenoid structures. These three chemicals show the general emission characteristics of PAHs, aryl-PAHs, and O-PAHs, respectively. Different emission characteristics are observed during the combustion and pyrolysis processes at lower oven temperatures. The minor emissions of O-PAHs observed in the pyrolysis process may be caused by the oxygen or oxygen 

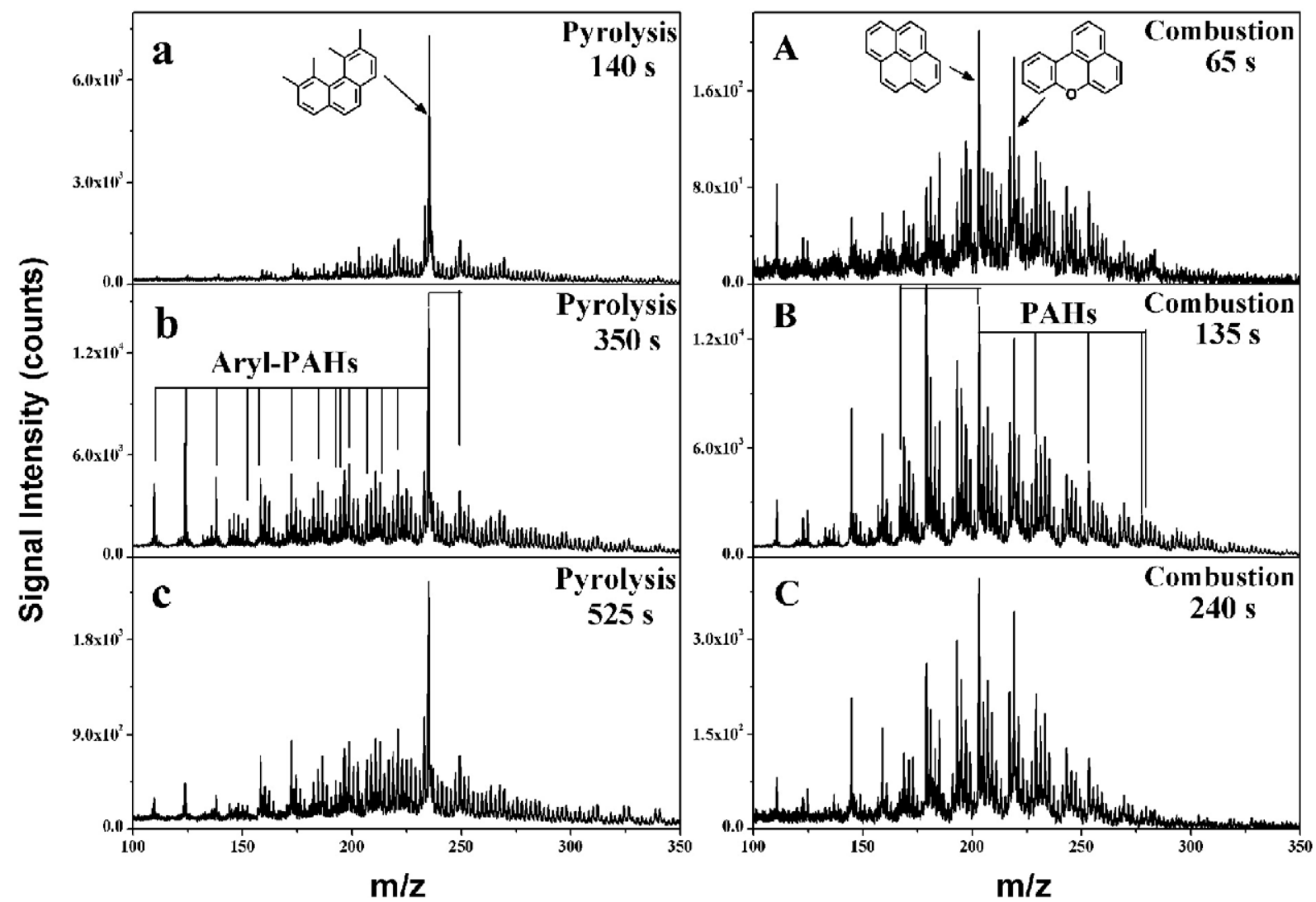

Fig. 4-VUV-TOF mass spectra of the coal soot particles generated in different stages of pyrolysis (a-c) and combustion (A-C) at 873 K. Fig. 4(a-c) are collected at 140 s, 350 s, and 525 s, respectively, while Fig. 4(A-C) are collected at 65 s, 135 s, and 240 s. The time is recorded after the coal sample is delivered into the center of the tube oven. All the mass spectra are collected for $30 \mathrm{~s}$.

containing chemicals contained in coal. Fig. 5 shows that the combustion process at $873 \mathrm{~K}$ emits more PAHs and O-PAHs than the pyrolysis process, whereas the pyrolysis process produces more aryl-PAHs than the combustion process. The emissions of the three kinds of the chemicals from combustion at $873 \mathrm{~K}$ decrease faster than those from pyrolysis. These phenomena can be explained by the formation of oxygencontaining radicals in the combustion process (Cao et al., 2003). The oxygen-containing radicals often react with the organic species in the form of $\mathrm{O}, \mathrm{OH}$ and $\mathrm{O}_{2} \mathrm{H}$ (Hucknell, 1985), and this results in the production of O-PAHs and more stable products (PAHs). The formation of oxygen-containing radicals leads to a faster decomposition of the organic compounds due to the increase of radical concentration or the increase of the reaction pathways (oxidation).

There are two limitations in this experiment. First, we did not measure the temperature of coal directly when burning. The combustion process is exothermic. We think that the temperature of the coal when burning should be higher than the temperature of the tube oven presented. Secondly, the VUVATOFMS is not uniform in the sensitivity to aromatic compounds and aliphatic compounds. GC/MS results show that there are mainly two classes of organic compounds in the particle phase of the IMB coal emissions, one is the aromatic compounds (1-7 rings) which is mainly divided into four subseries, e.g. PAHs, aryl-PAHs, cyclopenta-fused PAHs (CP-PAHs) and oxygen containing PAHs (O-PAHs) such as phenols, furans, aromatic alcohols, aromatic ketones and aromatic acids, another class is the aliphatic compounds including long chain alkanes and alkenes with molecular weights ranging from $170 \mathrm{Da}$ (Dodecane) to $507 \mathrm{Da}$ (Hexatriacontane). However, only mass peaks of the aromatic compounds are dominant in the mass spectra obtained, which means that the VUV-ATOFMS is more sensitive to aromatic compounds. Apparently, these two problems may bring about some distortion to understanding of the soot emissions of coal combustion and pyrolysis. Nevertheless, the capability of the on-line analysis of the VUVATOFMS is a good supplement to the instruments of off-line analyses such as GC/MS.

\section{Conclusions}

This paper reports the on-line analysis of the soot emission characteristics of the coal combustion and pyrolysis with a vacuum ultraviolet photoionization aerosol time-of-flight mass spectrometer. Based on the combination of the GC/MS TIC results and VUV photoionization mass spectra, we conclude that at lower oven temperatures $(<873 \mathrm{~K})$, the soot particles generated in combustion processes contained more O-PAHs, while those from pyrolysis contain more aryl-PAHs. At high temperatures, however, the soot particles from both combustion and pyrolysis contain mainly PAHs without any functional groups. The organics contained in coal undergo 

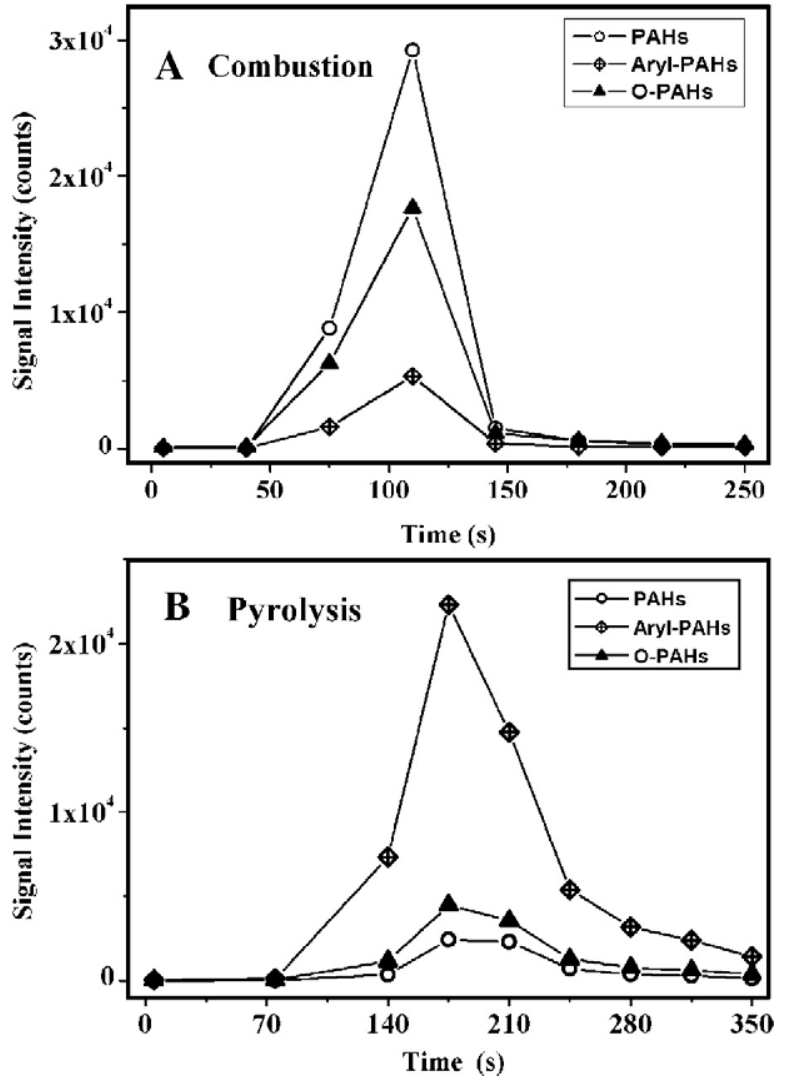

Fig. 5-The particle-phase emissions of phenanthrene, 3,4,5,6-tetramethylated phenanthrene, benzo[b]naphtha[2,3d]furan/benzo[k,l]xanthene at different combustion (A) and pyrolysis (B) times at $873 \mathrm{~K}$. Every data point shows the peak intensity of the corresponding compound on the VUV-TOF mass spectra, which is collected for $30 \mathrm{~s}$.

more rapid dissociation during the combustion process than the pyrolysis process at lower oven temperatures. The contents of soot particles generated in pyrolysis vary with the pyrolysis time. However, the chemical composition of the soot particles generated at different stages of combustion show no apparent differences under this experimental condition.

\section{Acknowledgements}

This research was supported by the funding for creative research groups of China (Grant No. 50621804) and the funding from National Natural Science Foundation of China (Grant No. 20673138). The authors would like to thank Dr. Maria Krisch for carefully editing the grammar of the manuscript.

\section{R E F E R E N C E S}

Arenillas A, Pevida C, Rubiera F, Garcia R, Pis JJ. Characterisation of model compounds and a synthetic coal by TG/MS/FTIR to represent the pyrolysis behaviour of coal. J Anal Appl Pyrolysis 2004;71:747-63.
Baxter LL, Richards GH, Ottesen DK, Harb JN. In-situ, real-time characterization of coal ash deposits using Fourier-transform infrared-emission spectroscopy. Energy Fuel 1993;7:755-60.

Canagaratna MR, Jayne JT, Jimenez JL, Allan JD, Alfarra MR, Zhang Q et al. Chemical and microphysical characterization of ambient aerosols with the aerodyne aerosol mass spectrometer. Mass Spectrom Rev 2007;26:185-222.

Cao L, Muhlberger F, Adam T, Streibel T, Wang HZ, Kettrup A, et al. Resonance-enhanced multiphoton ionization and VUV-single photon ionization as soft and selective laser ionization methods for on-line time-of-flight mass spectrometry: Investigation of the pyrolysis of typical organic contaminants in the steel recycling process. Anal Chem 2003;75:5639-45.

Chen YJ, Sheng GY, Bi XH, Feng YL, Mai BX, Fu JM. Emission factors for carbonaceous particles and polycyclic aromatic hydrocarbons from residential coal combustion in China. Environ Sci Technol 2005;39:1861-7.

Cooke WF, Liousse C, Cachier H, Feichter J. Construction of a 1 degrees $\times 1$ degrees fossil fuel emission data set for carbonaceous aerosol and implementation and radiative impact in the ECHAM4 model. J Geophys Res 1999;104:22137-62.

Dall'Osto M, Harrison RM, Charpantidou E, Loupa G, Rapsomanikis S. Characterisation of indoor airborne particles by using real-time aerosol mass spectrometry. Sci Total Environ 2007;384:120-33.

Davis WD. Surface ionization mass spectroscopy of airborne particulates. J Vac Sci Technol 1973;10:278.

Gao S, Zhang Y, Li Y, Meng J, He H, Shu J. A comparison between the vacuum ultraviolet photoionization time-of-flight mass spectra and the GC/MS total ion chromatograms of polycyclic aromatic hydrocarbons contained in coal soot and multi-component PAH particles. Int J Mass Spectrom 2008;274:64-9.

Gloaguen E, Mysak ER, Leone SR, Ahmed M, Wilson KR. Investigating the chemical composition of mixed organic-inorganic particles by "soft" vacuum ultraviolet photoionization: the reaction of ozone with anthracene on sodium chloride particles. Int J Mass Spectrom 2006;258:74-85.

Greenwood PF, Zhang E, Vastola FJ, Hatcher PG. Laser micropyrolysis gas-chromatography mass-spectrometry of coal. Anal Chem 1993;65:1937-46.

Hucknell, D.J., 1985. Chapman and Hall: London.

Ibarra JV, Moliner R. Coal characterization using pyrolysis FTIR. J Anal Appl Pyrolysis 1991;20:171-84.

Ledesma EB, Kalish MA, Nelson PF, Wornat MJ, Mackie JC. Formation and fate of $\mathrm{PAH}$ during the pyrolysis and fuel-rich combustion of coal primary tar. Fuel 2000;79:1801-14.

Lighty JS, Veranth JM, Sarofim AF. Combustion aerosols: factors governing their size and composition and implications to human health. J Air Waste Manage Assoc 2000;50:1565-618.

Mysak ER, Wilson KR, Jimenez-Cruz M, Ahmed M, Baer T. Synchrotron radiation based aerosol time-of-flight mass spectrometry for organic constituents. Anal Chem 2005;77:5953-60.

Northway MJ, Jayne JT, Toohey DW, Canagaratna MR, Trimborn A, Akiyama KI, et al. Demonstration of a VUV lamp photoionization source for improved organic speciation in an aerosol mass spectrometer. Aerosol Sci Technol 2007;41:828-39.

Oktem B, Tolocka MP, Johnston MV. On-line analysis of organic components in fine and ultrafine particles by photoionization aerosol mass spectrometry. Anal Chem 2004;76:253-61.

Olivella MA, del Rio JC, Palacios J, Vairavamurthy MA, de las Heras FXC. Characterization of humic acid from leonardite coal: an integrated study of PY-GC-MS, XPS and XANES techniques. J Anal Appl Pyrolysis 2002;63:59-68.

Oudejans L, Touati A, Gullett BK. Real-time, on-line characterization of diesel generator air toxic emissions by resonance-enhanced multiphoton ionization time-of-flight mass spectrometry. Anal Chem 2004;76:2517-24. 
Richter H, Howard JB. Formation of polycyclic aromatic hydrocarbons and their growth to soot - a review of chemical reaction pathways. Progr Energ Combust Sci 2000;26:565-608.

Schneider J, Weimer S, Drewnick F, Borrmann S, Helas G, Gwaze P, et al. Mass spectrometric analysis and aerodynamic properties of various types of combustion-related aerosol particles. Int J Mass Spectrom 2006;258:37-49.

Shu JN, Gao SK, Li Y. A VUV photoionization aerosol time-of-flight mass spectrometer with a RF-powered VUV lamp for laboratory-based organic aerosol measurements. Aerosol Sci Technol 2008;42:110-3.

Streibel T, Mitschke S, Adam T, Weh J, Zimmermann R. Thermal desorption/pyrolysis coupled with photo ionisation time-of-flight mass spectrometry for the analysis and discrimination of pure tobacco samples. J Anal Appl Pyrolysis 2007;79:24-32.

Sykes DC, Woods E, Smith GD, Baer T, Miller RE. Thermal vaporization-vacuum ultraviolet laser ionization time-of-flight mass spectrometry of single aerosol particles. Anal Chem 2002;74:2048-52.

Toner SM, Sodeman DA, Prather KA. Single particle characterization of ultrafine and accumulation mode particles from heavy duty diesel vehicles using aerosol time-of-flight mass spectrometry. Environ Sci Technol 2006;40:3912-21.

Woods E, Smith GD, Dessiaterik Y, Baer T, Miller RE. Quantitative detection of aromatic compounds in single aerosol particle mass spectrometry. Anal Chem 2001;73:2317-22. 